\title{
Experimental study of hardness effects on surface roughness for nanofluid minimum quantity lubrication (NanoMQL) technique using Jaya algorithm
}

\author{
Rahul R. Chakule ${ }^{a^{*}}$ and Sharad S. Chaudhari ${ }^{\mathrm{a}}$
}

\begin{tabular}{l} 
a Department of Mechanical Engineerih \\
\hline C H R O N I C L E \\
\hline Article history: \\
Received: May 1, 2018 \\
Received in revised format: June \\
16, 2018 \\
Accepted: August 18, 2018 \\
Available online: \\
August 18, 2018 \\
\hline Keywords: \\
Grinding \\
Jaya algorithm \\
Modeling \\
NanoMQL \\
Surface roughness
\end{tabular}

\section{Introduction}

The proper selection of machining process is the prime requirement of manufacturing industries in today's scenario. The process should be economical and environment friendly. In most of the industries, a large amount of coolant is used to reduce the friction and temperature occurred during machining either due to improper setting of process parameters or inefficient working process. The micro-lubrication techniques are widely used to overcome the limitations of wet technique (Brinksmeier et al., 2015; Kim et al., 2016; Najiha et al., 2016). Recently machining process integrated with recent technology called minimum quantity lubrication (MQL), Nanofluid minimum quantity lubrication (NanoMQL) and application of optimizer tools for optimal values are focused to obtain better grinding performance. The reason is complexity of grinding process due to more abrasive grits contact with wheel surface for microseconds and consumption of high specific grinding energy (Tawakoli et al., 2009). The better machining performance and surface integrity is obtained using MQL in comparison to other machining environments such

\footnotetext{
* Corresponding author. Tel.: +91 9922435720

E-mail address: r chakule@rediffmail.com (R. R. Chakule)

(C) 2018 by the authors; licensee Growing Science, Canada. doi: $10.5267 /$ j.ijdns.2018.8.002 A B S T R A C T

The NanoMQL technique is used to overcome the limitations of wet grinding due to economic ters such as table speed, depth of cut, air pressure, coolant flow rate and nanofluid concentration. In this paper, the performance of NanoMQL technique in terms of surface roughness was evaluology (RSM) using statistical software to develop regression model of surface roughness and optimization was carried out using Jaya algorithm. The result shows that lowest value of surface roughness was obtained for NanoMQL of hard steel in comparison with soft steel under grinding
environments such as wet, MQL and NanoMQL. Hence to improve the performance of soft steel, the modeling and optimization of surface roughness were carried out. The significant parameters (Anader for model development and validity of model determined through ANOVA imum surface roughness and the percentage error observed to be close with the experimental test.
\end{abstract}

(C) 2018 by the authors; licensee Growing Science, Canada. 
as dry, wet and process is more sustainable, human environment friendly (Chakule et al., 2017; Huang, et al., 2016; Mao et al., 2012; Hwang \& Lee, 2016). The suspended nanoparticles in base fluid significantly change the transport and heat transfer characteristics of suspension which increases the surface volume ratio, Brownian motion of nanoparticles (Godson et al., 2010; Sharma et al., 2011). The application of NanoMQL technique reduces the friction, cutting forces, specific energy and surface roughness largely when such nanofluid is applied to grinding zone as mist. The stable nanofluids of different concentrations are considered for grinding of NanoMQL experimentation. The better results in terms of grinding process efficiency and surface quality are obtained using small amount of cutting fluid (Zhang et al., 2015; Lee et al., 2015; Setti et al., 2015; Sinha et al., 2017; Zhang et al., 2016; Wang et al., 2017; Sinha et al., 2017; Kalita et al., 2012). The traditional method of optimization for NanoMQL process cannot predict the accurate guess of initial solution and may trap into local optima. The evolutionary optimization techniques are widely applied by the researchers to optimize the machining process parameters for machining performance and surface roughness (Gupta et al., 2016; Liu et al., 2017, Pai et al., 2013; Yusup et al., 2012).

During the last few years, some of the researchers have worked on grinding performance of soft and hard steel considering the dry, wet and MQL machining environments but to the best of authors' knowledge, no one has worked on hardness effect of EN31 steel for NanoMQL technique (Fig. 1). The surface quality is considered in the present study due to importance of quality production in industries. In this paper, the performance of surface roughness is studied for material hardness of EN31 under different grinding environments. Finally, the material of poor surface roughness is identified for NanoMQL technique and then it was analyzed by modeling and optimization for better value. The derived mathematical model was used as fitness function evaluation in Jaya algorithm.

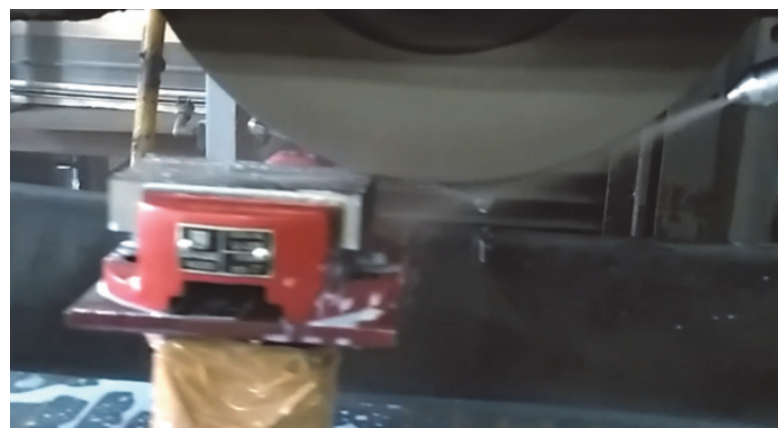

Fig. 1. Experimental setup

Table 1

Levels of process parameters

\begin{tabular}{cccccc}
\hline Level & $\begin{array}{c}\text { Table speed } \\
(\mathbf{m m} / \mathbf{m i n})\end{array}$ & $\begin{array}{c}\text { Depth of cut } \\
(\boldsymbol{\mu m})\end{array}$ & $\begin{array}{c}\text { Air pressure } \\
(\mathbf{b a r})\end{array}$ & $\begin{array}{c}\text { Coolant flow } \\
\text { rate (ml/hr) }\end{array}$ & $\begin{array}{c}\text { Nanofluid concentration } \\
(\mathbf{v o l .} \%)\end{array}$ \\
\hline Low $(-1)$ & 7000 & 20 & 2 & 250 & $0(\mathrm{MQL})$ \\
Medium $(0)$ & 10000 & 30 & 3 & 500 & 0.15 \\
High $(+1)$ & 13000 & 40 & 4 & 750 & 0.3 \\
\hline
\end{tabular}

\section{Experimental details}

The workpiece selected in the present experimental study was EN31 steel of hard and soft type. For hard material the hardness was maintained up to $58 \mathrm{HRC}$ and the same material without hardening was considered here as a soft steel of hardness $28 \mathrm{HRC}$. The experiments were conducted for both steel materials 
of rectangular plate of size $100 \times 50 \times 25 \mathrm{~mm}$ using horizontal surface grinding machine for different machining conditions such as wet, MQL and NanoMQL. The experiments were carried out with $\mathrm{Al}_{2} \mathrm{O}_{3}$ white corundum vitrified bond grinding wheel of size $500 \times 50 \times 203.2 \mathrm{~mm}$ and specification A-46-3-L5-V8. The stable $\mathrm{Al}_{2} \mathrm{O}_{3}$ nanofluid of concentrations 0.15 and 0.30 vol. \% for NanoMQL and $5 \%$ concentration of soluble oil in MQL were used for experimentation. The concentration (0) means the experiments are performed for MQL. The wheel dressing, nozzle position, parameter level selections were considered properly during experimentation as it significantly influences on the results. The importance of nozzle position for penetrating the cutting fluid into contact zone to obtain better surface finish was stated in paper (Mao et al. 2013). The homemade MQL setup was used for precise flow delivery in mist form at contact interface of wheel abrasive and workpiece surface. The quadratic model of surface roughness was formulated for selected range of parameters. The computer code was developed for Jaya algorithm to find optimal values for minimizing the surface roughness. The input parameters were coded as table speed (TS), depth of cut (DOC), air pressure (AP), coolant flow rate (CFR), nanofluid concentration (NC) whereas surface roughness $(\mathrm{Ra})$ is considered as response parameter. The average value of response was considered for analysis. The levels of parameters are shown in Table 1.

\section{Results and Discussion}

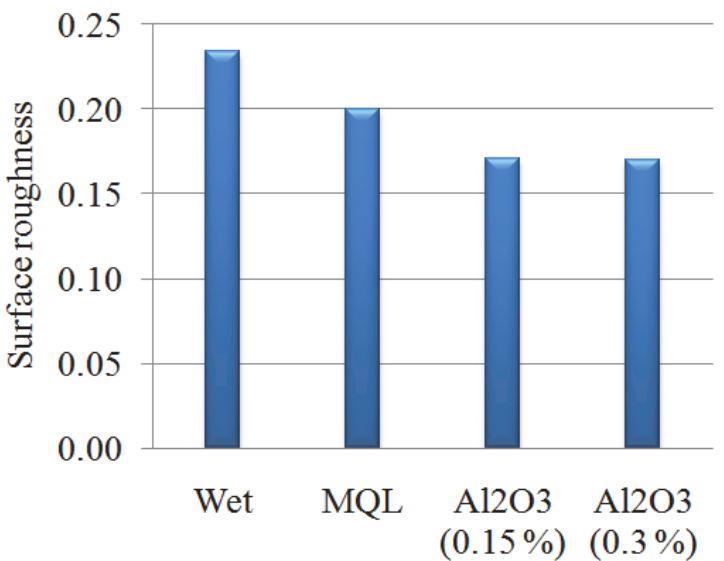

(a)

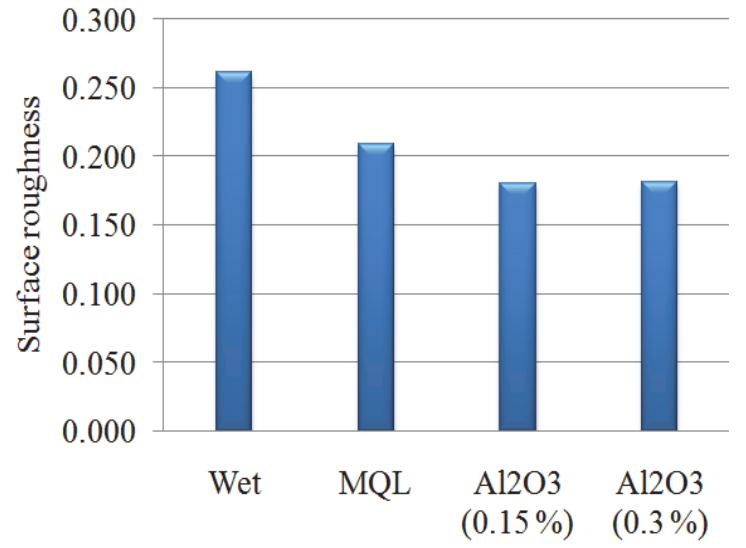

(b)

Fig. 2. Surface roughness under different cutting environments of (a) hard and (b) soft steel.

The results of surface roughness of hard and soft steel under different working environments such as wet, MQL and NanoMQL are shown in Fig. 2. The surface roughness of hard steel obtained under wet and MQL grinding environments are $0.234 \mu \mathrm{m}$ and $0.2 \mu \mathrm{m}$ respectively whereas the lowest value of surface roughness $0.17 \mu \mathrm{m}$ obtained in NanoMQL at 0.30 vol. \% concentration. Similarly for soft steel the lowest value of surface roughness $0.18 \mu \mathrm{m}$ was obtained in NanoMQL whereas for wet and MQL the surface roughness values obtained were $0.262 \mu \mathrm{m}$ and $0.21 \mu \mathrm{m}$, respectively. The poor surface quality of soft material is due to ductile fracture mechanism of higher material malleability and elongation before fracture which gives high material deformation and surface defects. For hardened steel, the brittle chip mechanism of material removal was observed. The trend of responses of hard and soft steel materials under dry, wet and MQL working conditions were discussed by Rabiei et al. (2015). The NanoMQL grinding gives the lowest surface roughness value compared to wet and MQL due to tribofilm of nanoparticles under extreme pressure on workpiece surface which reduces the friction and maintained cutting grits sharpness. The lubricity and cooling effects are more dominant in NanoMQL due to better lubricity properties of nanofluid and cooling effects by compressed air. In wet and MQL grinding, the soluble oil was used as cutting fluid and having poor lubricity. Again in wet grinding, the poor penetration of cutting fluid into high hydrodynamic pressure-grinding zone occurred due to high rotation of grinding wheel. Thus the poor lubricity and inefficient penetration of cutting fluid generates high value of surface roughness in wet grinding whereas the better penetration and removal of debris from cutting zone was possible 
in MQL due to high air pressure which gives better surface finish. The generation of lower forces due to better heat transfer characteristics of nanofluid using MQL may be the reason to obtain better surface finish in NanoMQL. The mode of material removal is more shearing in NanoMQL of hard steel whereas more deformation and ploughing in case of wet grinding. In order to improve the surface finish, the process parameters of soft steel are optimized using Jaya algorithm.

\section{Modeling and Optimization}

The regression equation was developed by RSM to improve the performance of NanoMQL grinding process of soft steel material. The mathematical model of surface roughness in terms of significant independent parameters is represented in Eq. (1). The independent parameters are coded as: table speed 'TS' $\left(\mathrm{x}_{1}\right)$, depth of cut 'DOC' $\left(\mathrm{x}_{2}\right)$, coolant flow rate 'CFR' $\left(\mathrm{x}_{3}\right)$ and nanofluid concentration ' $\mathrm{NC}$ ' $\left(\mathrm{x}_{4}\right)$ whereas the response parameter is surface roughness $(\mathrm{Ra})$. The numbers of experiments are reduced and determined based on central composite design (CCD) technique of RSM (Montgomery, 2013).

$$
\begin{aligned}
& R a=0.11201+0.000010 x_{1}-0.000361 x_{2}-0.000026 x_{3}-0.1427 x_{4}+0.6656 x_{4} * \\
& x_{4}=0.000015 x_{1} * x_{4}
\end{aligned}
$$

Table 2

ANOVA table of surface roughness of soft EN31 steel

\begin{tabular}{lllllll}
\hline Source & DF & Adj SS & Adj MS & F-value & P-value & Remarks \\
\hline Model & 6 & 0.016665 & 0.002777 & 75.17 & 0.000 & Significant \\
TS & 1 & 0.009522 & 0.009522 & 257.71 & 0.000 & Significant \\
DOC & 1 & 0.000235 & 0.000235 & 6.35 & 0.018 & Significant \\
CFR & 1 & 0.000787 & 0.000787 & 21.29 & 0.000 & Significant \\
NC & 1 & 0.003612 & 0.003612 & 97.77 & 0.000 & Significant \\
NC $\times$ NC & 1 & 0.001766 & 0.001766 & 47.80 & 0.000 & Significant \\
TS $\times$ NC & 1 & 0.000743 & 0.000743 & 20.10 & 0.000 & Significant \\
Lack of fit & 20 & 0.000774 & 0.000039 & 1.29 & 0.419 & \\
Pure error & 5 & 0.000150 & 0.000030 & & & \\
Total & 31 & 0.017588 & & & & \\
\hline
\end{tabular}

The $\mathrm{R}^{2}$ value of surface roughness is 0.9475 which is close to 1 , whereas pred $\mathrm{R}$-squared value 0.9172 is in good agreement with adj R-squared value of 0.9349 . This value indicates that the model was well fitted by the data. The P-value of parameters less than 0.05 indicates that the model terms were significant. The F-value of table speed means table speed is influential parameter in response. The ANOVA table of surface roughness of soft steel is shown in Table 2.

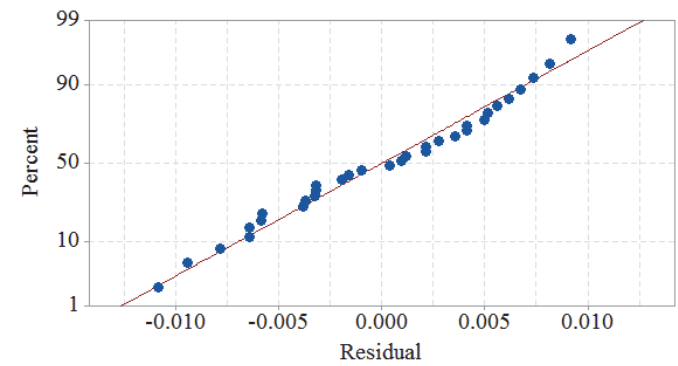

Fig.3. Normal probability plot of surface roughness of EN31 soft steel

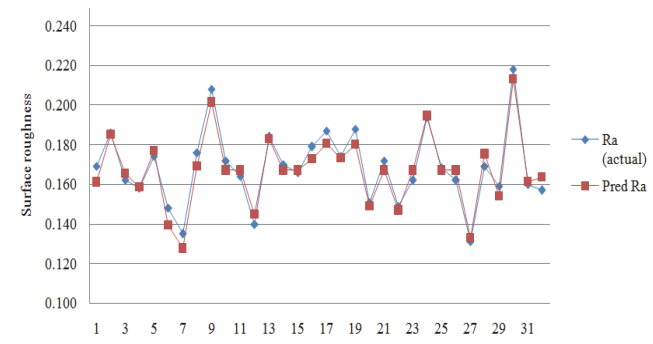

Fig. 4. Experimental and predicted values of surface roughness of EN31 soft steel 
It was also observed that the residuals lie along and around the straight line. It indicates that the errors are normally distributed and model is adequate to study the relationship between independent parameters and response. The normal probability plot of surface roughness and comparison between experimental and predicted values are shown in Figs. (3-4).

\subsection{Optimizing of surface roughness}

From literature studies it was observed that all the evolutionary algorithms are probabilistic and requires common controlling parameters like population size and the number of iterations. Again different algorithms require their own algorithm-specific control parameters. The improper tuning of algorithm-specific parameters either increases the computational effort or yields the local optimal solution. In this research work the developed model is optimized using coded Jaya algorithm to obtain optimal values of parameters for minimizing the response using Eq. (1). The reason is that Jaya algorithm is free from such common controlling and algorithm specific parameters. The Jaya algorithm is simple and is able to get the optimal solutions with fewer number of function evaluations and memory requirement (Rao et al., 2017; Rao et al., 2016; Rao, 2017; Rao, 2016). The regression equation developed is subject to constraint such as $7000 \leq \mathrm{TS} \leq 13000,20 \leq \mathrm{DOC} \leq 40,250 \leq \mathrm{CFR} \leq 750$ and $0 \leq \mathrm{NC} \leq 0.30$. The algorithm is based on the concept that the final solution should be the best one and avoid the worst solution. The algorithm always tries to move closer to success (i.e. reaching the best solution) and avoid failure (i.e. moving away from the worst solution). The $\mathrm{f}(\mathrm{x})$ is the objective function to be minimized.

$$
X_{j, k, i}^{\prime}=X_{j, k, i}+r_{1, j, i}\left(X_{j, b e s t, i}-\left|X_{j, k, i}\right|\right)-r_{2, j, i}\left(X_{j, w o r s t, i}-\left|X_{j, k, i}\right|\right),
$$

where $X_{j, b e s t, i}$ is the value of the variable $j$ for the best candidate and $X_{j, \text { worst,i }}$ is the value of the variable $j$ for the worst candidate. $X_{j, k, i}$ is the updated value of $X_{j, k, i}$ and $r_{1, j, i}$ and $r_{2, j, i}$ are the two random numbers for the $\mathrm{j}^{\text {th }}$ variable during the $\mathrm{i}^{\text {th }}$ iteration in the range $(0,1)$. The term " $\mathrm{r}_{1, \mathrm{j}, \mathrm{i}}\left(\mathrm{X}_{\mathrm{j}, \text { best,i }}-\left|\mathrm{X}_{\mathrm{j}, \mathrm{k}, \mathrm{i}}\right|\right)$ " indicates the tendency of the solution to move closer to the best solution and the term " $-r_{2, j, i}\left(X_{j, \text { worst, }}{ }_{-}\left|X_{j, k, i}\right|\right)$ " indicates the tendency of the solution to avoid the worst solution. $X^{\prime}{ }_{j, k, i}$ is accepted if it gives better function value. All the accepted function values at the end of iteration are maintained and become the input to the next iteration. The random numbers $r_{1}$ and $r_{2}$ ensure good exploration of the search space. The absolute value of the candidate solution $\left(\left|\mathrm{X}_{\mathrm{j}, \mathrm{k}, \mathrm{i}}\right|\right)$ considered in Eq. (2) further enhances the exploration ability of the algorithm.

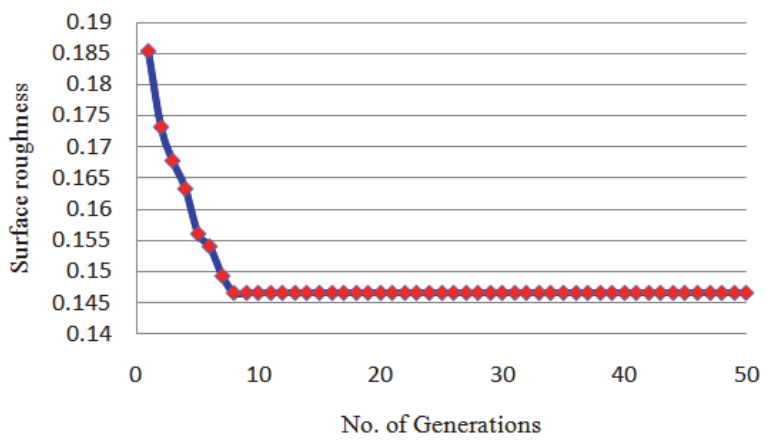

Fig. 5. Convergence graph of surface roughness of EN31 soft steel

Table 3

Optimal values and confirmation experiments of soft steel using Jaya algorithm

\begin{tabular}{cccccccc}
\hline TS & DOC & CFR & NC & $\begin{array}{c}\text { Predicted Ra } \\
(\boldsymbol{\mu m})\end{array}$ & $\begin{array}{c}\text { Experimental test } \\
\mathbf{R a}(\boldsymbol{\mu m})\end{array}$ & $\begin{array}{c}\text { Elapsed } \\
\text { time (s) }\end{array}$ & $\begin{array}{c}\text { Convergence after } \\
\text { number of generation }\end{array}$ \\
\hline 7000 & 20 & 750 & 0.186 & 0.1466 & 0.138 & 18.34 & 8 \\
\hline
\end{tabular}

The convergence curve to optimize the surface roughness of soft steel is shown in Fig. (5). It shows that the convergence graph lower continuously until it reaches the lowest value of surface roughness and then remains stable. This shows that the Jaya algorithm is robust and does not get trapped in local optima. 
The optimal values, elapsed time and convergence values after number of generations are summarized in Table 3. The number of generations and population selected are 50 and 100, respectively. The experimental tests were conducted at optimal feasible values of parameters to validate the results obtained from Jaya algorithm. The minimum surface roughness of $0.1466 \mu \mathrm{m}$ predicted by Jaya was in good agreement with result of experiment test $(0.138 \mu \mathrm{m})$. The optimal values obtained from Jaya algorithm is really beneficial to improve the performance of grinding of soft steel with NanoMQL technique.

\section{Conclusions}

The hardness effect of EN31 steel under different grinding environments such as wet, MQL and NanoMQL for minimizing the surface roughness was studied. Further the Jaya algorithm is used for optimization of soft steel to obtain optimal values for enhancing the surface quality. The results obtained in this study are summarized as follows:

- The lowest surface roughness is obtained in NanoMQL technique of hard steel. The reduction in surface roughness value of hard steel are obtained by $5.88 \%$ in NanoMQL at $0.30 \mathrm{vol} . \%$ concentration, $5 \%$ in MQL and $11.96 \%$ in wet grinding over the soft steel material. The reasons are less friction at contact interface in comparison to other cutting environments due to efficient lubrication and cooling effects. The surface quality is improved in fewer amounts of cutting fluid compared to wet and MQL grinding environments. In hard material the brittle fracture occurred, due to which surface damage and defects are comparatively less than soft steel.

- To improve the surface quality of soft steel, the modeling and optimization of surface roughness is performed. The quadratic model of surface roughness was formulated for significant parameters and its adequacy was checked by ANOVA to predict the surface roughness of soft steel at $95 \%$ confidence interval. The optimal values obtained from Jaya algorithm are TS (7000 $\mathrm{mm} / \mathrm{min})$ DOC $(20 \mu \mathrm{m})$, CFR $(750 \mathrm{ml} / \mathrm{hr})$ and NC $(0.186 \mathrm{vol} . \%)$. The predicted value of surface roughness obtained from modeling is $0.1466 \mu \mathrm{m}$. The experimental tests were conducted to confirm the optimal values determined from Jaya algorithm. The surface roughness obtained through experimental test is $0.138 \mu \mathrm{m}$ shows the percentage error of $5.87 \%$. The good agreement in results of surface roughness obtained with predicted and experimental value.

- The convergence accuracy and speed of Jaya algorithm is very high. The better grinding results are obtained at optimal values with less function evaluations and memory requirement. The results obtained from Jaya algorithm are really beneficial to improve the surface finish of NanoMQL grinding process especially of soft steel.

\section{Acknowledgements}

The authors are thankful to the Sir Dr. M. S. Gosavi Pharmaceutical College to provide facilities for nanofluids preparation, Visvesvaraya National Institute of Technology (VNIT) and North Maharashtra University (NMU) for characterization of the nanofluids. The authors are also grateful to Sameeksha Industries for providing the resources to work completion.

\section{References}

Brinksmeier, E., Meyer, D., Huesmann-Cordes, A.G., \& Herrmann, C. (2015). Metal working fluidsMechanisms and performance, CIRP Annals, 64 (2), 605-628.

Chakule, R.R., Chaudhari, S.S., \& Talmale, P.S. (2017). Evaluation of the effects of machining parameters on MQL based surface grinding process using response surface methodology. Journal of Mechanical Science and Technology, 31(8), 3907-3916.

Godson, L., Raja, B., Mohan Lal, D., \& Wongwises, S. (2010). Enhancement of heat transfer using nanouids- A overview. Renewable and Sustainable Energy Reviews, 14, 629-641. 
Gupta, M.K., Sood, P.K., \& Sharma, V.S. (2016). Optimization of machining parameters and cutting fluids during nanofluid based minimum quantity lubrication turning of titanium alloy by using evolutionary techniques. Journal of Cleaner Production, 135, 1276-1288.

Huang, X., Ren, Y., Jiang, W., He, Z., \& Deng, Z. (2017). Investigation on grind-hardening annealed AISI5140 steel with minimal quantity lubrication. International Journal Advanced Manufacturing Technology, 89 (1-4), 1069-1077.

Hwang, Y.K., \& Lee, C.M. (2010). Surface roughness and cutting force prediction in MQL and wet turning process of AISI 1045 using design of experiments. Journal of Mechanical Science and Technology, 24(8), 1669-1677.

Kalita, P., Malshe, A.P., Arun Kumar, S., Yoganath, V.G., \& Gurumurthy, T. (2012). Study of specific energy and friction coefficient in minimum quantity lubrication grinding using oil-based nanolubricants. Journal of Manufacturing Processes, 14(2), 160-166.

Kim, H-J., Seo, K-J., Kang, K.H., \& Kim, D-E. (2016). Nano-Lubrication: A Review. International Journal of Precision Engineering and Manufacturing, 17(6), 829-841.

Lee, P.H., Lim, S.H., Lee, S.H., Ko, H.S., \& Shin, S.W. (2015). A study on thermal characteristics of micro-scale grinding process using nanofluid minimum quantity lubrication (MQL). Precision Engineering and Manufacturing, 16(9), 1899-1909.

Liu, G., Li, C., Zhang, Y., Yang, M., Jia, D., Zhang, X., Guo, S., Li, R., \& Zhai, H. (2017). Process parameter optimization and experimental evaluation for nanofluid MQL in grinding Ti-6Al-4V based on grey relational analysis. Materials and Manufacturing Processes. 33(9), 1-14.

Mao, C., Tang, X., Zou, H., Zhou, Z., \& Yin, W. (2012). Experimental investigation of surface quality for minimum quantity oil-water lubrication grinding. International Journal of Advanced Manufacturing Technology, 59, 93-100.

Mao, C., Zou, H., Huang, X., Zhang, J., \& Zhou, Z. (2013). The influence of spraying parameters on grinding performance for nanofluid minimum quantity lubrication. International Journal of Advanced Manufacturing Technology, 64 (9-12), 1791-1799.

Montgomery, D.C. (2013). Design and Analysis of Experiments, 8th ed. Wiley, New York.

Najiha, M.S., Rahman, M.M., \& Yusoff, A.R. (2016). Environmental impacts and hazards associated with metal working fluids and recent advances in the sustainable systems: A review. Renewable and Sustainable Energy Reviews, 60, 1008-1031.

Pai, D., Rao, S., \& DSouza, R. (2013). Application of response surface methodology and enhanced nondominated sorting genetic algorithm for optimization of grinding process. Procedia Engineering, 64, 1199-1208.

Rabiei, F., Rahimi, A.R., Hadad, M.J., \& Ashrafijou M. (2015). Performance improvement of minimum quantity lubrication (MQL) technique in surface grinding by modeling and optimization. Journal of Cleaner Production, 86, 447-460.

Rao, R.V., Rai, D.P., \& Balic, J. (2017). A new optimization algorithm for parameter optimization of nano-finishing processes. Scientia Iranica E, 24(2), 868-875.

Rao, R.V., Rai, D.P., Ramkumar, J., \& Balic, J. (2016). A new multi-objective Jaya algorithm for optimization of modern machining processes. Advances in Production Engineering \& Management, 11(4), 271-286.

Rao, R.V. (2017). A Multi-objective algorithm for optimization of modern machining processes. Engineering Applications of Artificial Intelligence, 61, 103-125.

Rao, R.V. (2016). Jaya: A simple and new optimization algorithm for solving constrained and unconstrained optimization problems. International Journal of Industrial Engineering Computations, 7, 1934.

Setti, D., Sinha, M.K., Ghosh, S., \& Rao, P.V. (2015). Performance evaluation of Ti-6Al-4V grinding using chip formation and coefficient of friction under the influence of nanofluids. Machine Tools and Manufacture, 88, 237-248.

Sharma, P., Baek, I-H., Cho, T., Park, S., \& Lee, K.B. (2011). Enhancement of thermal conductivity of ethylene glycol based silver nanouids. Powder Technology, 208, 7-19.

Sinha, M.K., Madarkar, R., Ghosh, S., \& Rao, P.V. (2017). Application of eco-friendly nanofluids during 
grinding of Inconel 718 through small quantity lubrication. Journal of Cleaner Production, 141, 1359-1375.

Tawakoli, T., Hadad, M.J., Sadeghi, M.H., Daneshi, A., Stockert, S., \& Rasifard, A. (2009). An experimental investigation of the effects of workpiece and grinding parameters on minimum quantity lubrication-MQL grinding. International Journal of Machine Tools and Manufacture, 49(12-13), 924-932.

Wang, Y., Li, C., Zhang, Y., Yang, M., Zhang, X., Zhang, N., \& Dai, J. (2017). Experimental evaluation on tribological performance of the wheel/workpiece interface in minimum quantity lubrication grinding with different concentrations of A12O3 nanofluids. Journal of Cleaner Production, 142(4), 3571-3583.

Yusup, N., Zain, A.M., \& Mohd Hashim, S.Z. (2012). Evolutionary techniques in optimizing machining parameters: Review and recent applications (2007-2011). Expert Systems with Applications, 39, 99099927.

Zhang, D., Li, C., Zhang, Y., Jia, D., \& Zhang, X. (2015). Experimental research on the energy ratio coefficient and specific grinding energy in nanoparticle jet MQL grinding. International Journal of Advanced Manufacturing Technology, 78, 1275-1288.

Zhang, Y., Li, C., Jia, D., Li, B., Wang, Y., Yang, M., Hou, Y., \& Zhang, X. (2016). Experimental study on the effect of nanoparticle concentration on the lubricating property of nanofluids for MQL grinding of Ni-based alloy. Journal of Materials Processing Technology, 232,100-115.

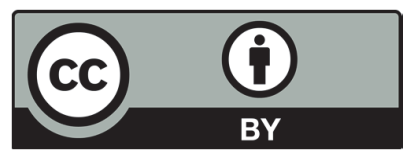

(C) 2018 by the authors; licensee Growing Science, Canada. This is an open access article distributed under the terms and conditions of the Creative Commons Attribution (CCBY) license (http://creativecommons.org/licenses/by/4.0/). 